ЧУВСТВИТЕЛЬНОСТЬ ОПУХОЛИ, ТРАНСПЛАНТИРОВАННОЙ БЕСТИМУСНЫМ МЫШАМ ИЗ КУЛЬТУРЫ КЛЕТОК РАКА ВУЛЬВЫ, К ОНКОЛИТИЧЕСКОМУ ДЕЙСТВИЮ НОВОЙ НЕКЛАССИФИЦИРОВАННОЙ ГРУППЫ РОТАВИРУСОВ CEMEЙCTBA REOVIRIDAE.

\author{
Златник Е.Ю. ${ }^{1}$ Колпаков С.А. 2 , Колпакова Е.П. ${ }^{2}$, Вереникина Е.В. ${ }^{1}$, Абдуллаева Н.М.1, \\ Шульгина О.Г. ${ }^{1}$, Ситковская А.О.. ${ }^{1}$, Быкадорова О.В. ${ }^{1}$
}

${ }^{1}$ Федеральное государственное бюджетное учреждение «Ростовский научно-исследовательский онкологический институт» Минздрава России, Ростов-на-Дону, e-mail: elena-zlatnik@mail.ru;

${ }^{2}$ Федеральное бюджетное учреждение науки «Ростовский НИИ микробиологии и паразитологии» Роспотребнадзора, Ростов-на-Дону

Цель: изучение действия штаммов новой неклассифицированной группы ротавирусов человека семейства Reoviridae на рост эпидермоидной карциномы человека A431 (рака вульвы) в эксперименте. Использовали штаммы № 100 и № 228 новой группы ротавирусов с рабочим названием RVK, живые аттенуированные, апатогенные. Культуру эпидермоидной карциномы A431 (рак вульвы) перевивали 15 бестимусным мышам линии Balb/cNude, создавая CDX-опухоль. После образования опухоли двум опытным группам мышей еженедельно паратуморально вводили по 0,3 мл живых RVK № 100 и № 228 в концентрации 5x10/Мл, всего 5 инъекций; третья группа была контрольной и получала физиологический раствор. Определяли динамику роста опухоли и ее объем, рассчитывали индекс и процент торможения опухолевого роста; через 2 месяца оценивали клеточный иммунитет. У мышей опытных групп торможение роста опухоли отмечается во все сроки наблюдения и продолжается 7 недель после перевивки при введении RVK штамма № 100, процент торможения роста опухоли достигал максимума через $3-4$ недели, составляя 44-52\%. Для штамма № 228 уменышение объема опухоли не было статистически значимым, однако с 3-й недели до конца наблюдения у них отмечена тенденция к уменышению объема опухоли и увеличивался процент торможения опухоли до 30-37\%. Финальный объем опухоли у опытных животных, получавших штамм № 100, был в 2,7 раза ниже контроля, а у получавших штамм № 228 - в 1,9 раза ниже. У мышей, получавших RVK штамма № 100, уровень В-клеток имел тенденцию к повышению по сравнению с контролем. На СDХ-модели эпидермоидной карциномы человека (рака вульвы) у бестимусных мышей установлено торможение под действием RVK, что свидетельствует о наличии у них (преимущественно со штаммом № 100) онколитических свойств.

Ключевые слова: культура эпидермоидной опухоли вульвы, онколитические вирусы, торможение опухолевого роста.

\title{
SENSITIVITY OF TUMOR TRANSPLANTED TO ATHYMIC MICE FROM VULVAR CARCINOMA CELL LINE TO ONCOLYTIC EFFECT OF A NEW GROUP OF NON- CLASSIFIED HUMAN ROTAVIRUS OF REOVIRIDAE FAMILY
}

\author{
Zlatnik E.Y. ${ }^{1}$, Kolpakov S.A. ${ }^{2}$, Kolpakova E.P. ${ }^{2}$, Verenikina E.V. ${ }^{1}$, Abdullaeva N.M. ${ }^{1}$, \\ Shulgina O.G. ${ }^{1}$, Sitkovskaya A.O. ${ }^{1}$, Bykadorova O.V. ${ }^{1}$
}

${ }^{1}$ Rostov Research Institute of Oncology, Rostov-on-Don,e-mail: elena-zlatnik@mail.ru;

${ }^{2}$ Rostov Research Institute of Microbiology and Parasitology, Rostov-on-Don

The aim: to assess the effect of two new non-classified rotavirus strains of Reoviridae family on the growth of human vulvar epidermoid carcinoma A431 transplanted to nude mice. We studied two strains of the new group of rotavirus (RVK): № 100 and № 228 (http://jbks.ru/archive/issue-10/article-6). CDX-tumor was established by transplantation of A431 to 15 Balb/cNude mice 22-24 g body weight. After formation of tumors paratumoral administration of $0.3 \mathrm{ml}$ of alive RVK № 100 and № $228\left(5 \times 10^{9} / 1 \mathrm{ml}\right)$ was performed weekly during 5 weeks. The control group received $0.85 \% \mathrm{NaCl}$. Tumor growth rate and volume were measured, index and per cent of tumor inhibition were calculated. After 2 months cell-mediated immunity was assessed. In mice injected with RVK tumor growth inhibition was noted aftter 2 weeks of monitoring only in strain № 100; the trend was observed during the whole time up to 7 weeks with maximal per cent of tumor inhibition 44-52\% reached in 3-4 weeks. Mice receiving strain № 228 demonstrated a tendency to the lower tumor volumes in 3-7 weeks, with 30-37\% of tumor inhibition. Final tumor volume in animals receiving strain № 100 was 2.7 times lower and in case of strain № 228 it was 1.9 times less than in controls. Group receiving strain № 100 had a tendency to an increase of B-cells` levels against controls. In the in vivo model of human vulvar epidermoid carcinoma A431 transplanted to nude mice inhibition of tumor growth under RVK administration was established due to oncolytic activity of RVK, mainly № 100. 
Keywords: culture of epidermoid tumor of the vulva, oncolytic viruses, inhibition of tumor growth.

Повсеместное значительное увеличение количества онкологических заболеваний, несмотря на большой арсенал противораковых средств их лечения, заставляет искать новые способы борьбы с ними. В последнее время бурно развивается направление по использованию вирусов различных вариантов (природных и сконструированных) для достижения онколитического эффекта $[1,2]$.

Считается, что онколитические вирусы обладают как прямым, так и опосредованным через иммунную систему действием, однако вклад каждого из этих эффектов в конечный результат, т.е. в торможение роста опухоли или ее регрессию, остается предметом обсуждения $[3,4]$. Учитывая широкое применение в онкологических исследованиях иммунодефицитных животных, можно заключить, что именно они являются оптимальными моделями для разграничения иммуностимулирующего и собственно онколитического действия, хотя в работах, ориентированных на клиническое применение виротерапии, она все чаще упоминается в контексте комплексных и комбинированных, в том числе с иммунотерапией, подходов [5].

Эпидермоидная карцинома А431 представляет собой клеточную линию, выделенную из рака вульвы человека. Учитывая локализацию таких опухолей, они, как и рак шейки матки, часто развиваются в организме, инфицированном вирусами, из которых наиболее изучен вирус папилломы человека (ВПЧ), причем во многих работах сообщается о том, что именно у таких больных чаще наблюдается благоприятный прогноз заболевания. Несмотря на то что ВПЧ-инфекция считается этиологическим фактором этих опухолей, на основании метаанализа 33 работ, выполненных в различных странах мира, был сделан вывод о более благоприятном течении рака вульвы при наличии ВПЧ [6], что свидетельствует о том, что действие даже такого вируса с доказанной онкогенной ролью может быть не только негативным. Представляет несомненный интерес исследование вирусов с онколитическим потенциалом на CDX-модели (cell-derived xenograft) эпидермоидной карциномы A431.

В Ростовском институте микробиологии и паразитологии из фекальных экстрактов детей, больных ротавирусной инфекцией, старшим научным сотрудником к.м.н. С.А. Колпаковым были выделены два штамма ротавирусов (№ 228 и № 100), получивших рабочее название - «ротавирусы группы К (RVK)», поскольку не удалось отнести их ни к одной из известных групп ротавирусов. Штаммы были охарактеризованы как ротавирусные электронно-микроскопическими, серологическими и генетическими методами, аттенуированы и в настоящее время являются апатогенными [7]. Аттенуацию RVK человека проводили путем многократных пассажей (более 80) на гетерологичной культуре 
перевиваемых клеток эмбриона свиньи (СПЭВ) в среде 199 с добавлением 10\% сыворотки крупного рогатого скота. Апатогенность аттенуированных штаммов проверяли на белых беспородных мышах и крысятах, вводя им внутримышечно по 0,3 мл и 0,6 мл штаммов RVK соответственно, что значительно превышает величину максимально переносимой дозы, рекомендуемой при исследовании общетоксических свойств, - 1000 мг/кг. При этом все животные не только были живы, но и сохраняли биологическую активность, их физиологические функции, поведение, аппетит, температура тела и другие показатели не отличались от таковых в сравнении с контрольной группой животных в течение всего срока наблюдения (30 дней).

Нами ранее были показаны литическая и проапоптогенная активность RVK на культурах опухолевых клеток in vitro [8] и противоопухолевое действие в эксперименте на животных-опухоленосителях in vivo с применением различных моделей. В экспериментах на мышах линии C57/Black6 с перевиваемой меланомой B16/F10 при введении им RVK в режимах «вакцинация» и «лечение», т.е. до и после перевивки опухоли соответственно, было показано существенное повышение продолжительности жизни животных [9].

Целью данной работы явилось изучение действия штаммов новой неклассифицированной группы ротавирусов человека семейства Reoviridae на рост эпидермоидной карциномы человека А431 (рака вульвы) в эксперименте.

Материалы и методы исследования. Экспериментальные исследования проводили на 15 бестимусных мышах-самках линии Balb/cNude массой 22-24 г, полученных из «SPFвивария» ИЦиГ СО РАН (г. Новосибирск). Работа с животными осуществлялась в соответствии с правилами «Европейской конвенции о защите животных, используемых в экспериментах» (Директива 86/609/EЕС) и приказом Минздрава России от 19.06.2003 г. № 267 «Об утверждении правил лабораторной практики».

Культуру эпидермоидной карциномы А431, полученную из МНОЦ МГУ, использовали для перевивки после предварительного выращивания на 5 стерильных культуральных

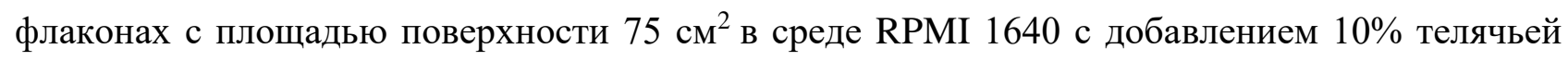
эмбриональной сыворотки и $0,5 \%$ пенициллина-стрептомицина. Снятие культуры с поверхности флаконов проводилось раствором Трипсин-Версена (1:3), подсчет клеток проводили в камере Горяева. Для перевивки животным клеточную суспензию отмывали от компонентов сыворотки и антибиотиков раствором Хенкса, разбавляли в питательной среде RPMI 1640 и перевивали под кожу бедра в количестве 5x106 клеток в условиях SPF-зоны вивария. После образования пальпируемых опухолей (через 1 неделю после перевивки) животным опытных групп начинали еженедельное паратуморальное введение живых RVK штаммов № 100 и № 228 соответственно, всего 5 инъекций по 0,3 мл с концентрацией 
вирусных частиц 5х10\%/мл. 3-я (контрольная) группа получала физиологический раствор. Определяли динамику роста опухоли и ее объем, который рассчитывали по формуле Шрека. Индекс торможения и процент торможения роста опухоли вычисляли по формулам: ИТ $=$ Vк/Vоп и $\mathrm{TPO}=[(\mathrm{V \kappa}-\mathrm{Voп}) / \mathrm{V}] \mathrm{x} 100 \%$ соответственно, где Vк - объем опухоли в контрольной группе; Vоп - объем опухоли в опытной группе. Через 2 месяца мышей подвергали эвтаназии, в крови определяли состав субпопуляций лимфоцитов (Т-, В-, NKклетки; В-клеточное звено: В220, CD23, sIgM) методом проточной цитометрии на анализаторе BD FACS Canto II, результаты выражали в процентах.

Статистическую обработку данных проводили с использованием программы Statistica 13. Поскольку группы были малочисленными и распределение показателей не являлось нормальным, данные обрабатывали с помощью непараметрического метода с определением U-критерия Манна-Уитни. Результаты представлены в виде медианы (Me), верхнего (UQ) и нижнего (LQ) квартиля (Me [UQ; LQ]). Статистически значимыми считали различия при $\mathrm{p}<0,05$, расценивали как тенденцию при $0,05<\mathrm{p}<0,1$.

\section{Результаты исследования и их обсуждение}

Результаты исследования представлены в таблице 1 и на рисунках 1-3. Как видно из таблицы 1, у мышей опытных групп значения объемов опухолей во все сроки исследования были меньше, чем у контрольных животных, особенно это касается мышей, получавших RVK штамма № 100. Статистически значимых отличий от контроля данный показатель достигает через 2 недели после перевивки и далее на протяжении всего срока наблюдения остается ниже контроля. Для RVK штамма № 228 статистически значимых отличий от контроля не найдено, хотя тенденция к снижению отмечена начиная с 3-й недели после перевивки опухоли.

Таблица 1

Влияние введения RVK на объем опухолей мышей в динамике наблюдения

\begin{tabular}{|c|c|c|c|c|c|}
\hline \multirow{2}{*}{$\begin{array}{c}\text { Сроки после } \\
\text { перевивки } \\
\text { (недель) }\end{array}$} & \multicolumn{5}{|c|}{ Показатели V опухоли $\left(\mathrm{cm}^{3}\right)$} \\
\cline { 2 - 6 } & № $100[\mathrm{LQ} ; \mathrm{UQ}]$ & $\mathrm{p}$ & (Me) [LQ; UQ] & $\mathrm{p}$ & Контроль \\
\hline 2 & $2,4[1,21 ; 3,01]$ & $0,045^{*}$ & $2,9[2,47 ; 3,31]$ & 0,22 & $3,16[3,1 ; 4,65]$ \\
\hline 3 & $2,55[0,825 ; 4,8]$ & $0,047^{*}$ & $4,2[3,6 ; 5,15]$ & $0,054^{* *}$ & $5,15[4,4 ; 7,3]$ \\
\hline 4 & $3,1[1,1 ; 4,1]$ & $0,028^{*}$ & $5,6[2,5 ; 6,65]$ & $0,053^{* *}$ & $6,32[4,3 ; 6,4]$ \\
\hline 5 & $5,36[1,49 ; 6,4]$ & $0,021^{*}$ & $7,3[3,17 ; 11,97]$ & $0,088^{* *}$ & $10,15[7,82 ; 15,9]$ \\
\hline 6 & $5,85[1,1 ; 6,45]$ & $0,016^{*}$ & $7,7[3,13 ; 13,8]$ & $0,05^{* *}$ & $11,15[7,55 ; 19,9]$ \\
\hline 7 & $6,6[2,0 ; 9,7]$ & $0,03^{*}$ & $7,8[3,9 ; 11,9]$ & $0,053^{* *}$ & $13,5[10,5 ; 21,45]$ \\
\hline
\end{tabular}

Примечание. * - статистически значимые отличия от контроля $(\mathrm{p}<0,05) ;{ }^{*}$ - тенденция к отличию от контроля $(0,05<\mathrm{p}<0,1)$.

На рисунке 1 представлена динамика процента торможения роста опухоли, иллюстрирующая, что при применении штамма RVK № 100 через 3-4 недели после перевивки 
показатели выходят на плато, соответствующее 44-52\%, а для штамма RVK № 228 такое плато наступает позже (через 37 дней), и нарастание показателя продолжается до 50-го дня после перевивки. Индекс торможения опухоли также был выше у мышей, получавших штамм № 100, и составлял в разные сроки исследования от 1,9 до 2,5, тогда как при введении штамма № 228 - от 1,4 до 1,8 .

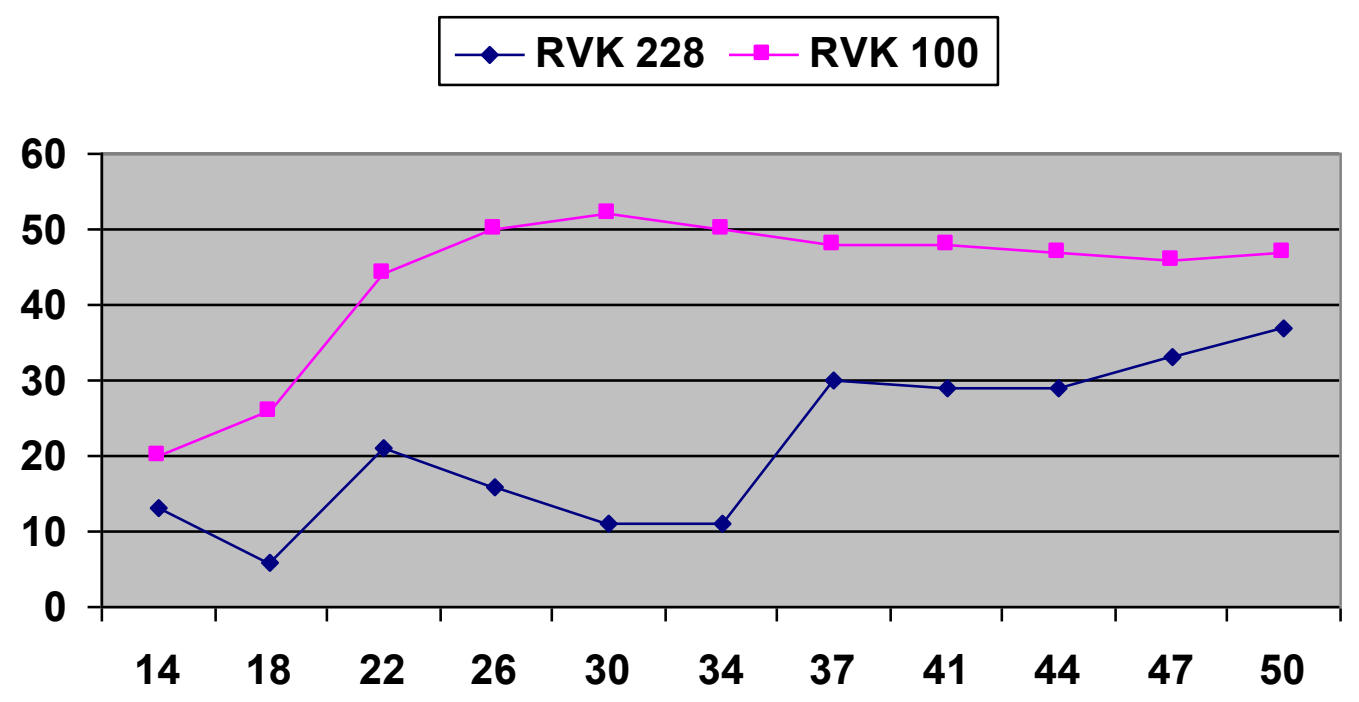

Pис. 1. ТРО А431 в динамике при введении RVK штаммов № 228 и № 100. Ось X-сутки после перевивки опухоли; ось $Y-T P O(\%)$

Как видно из рисунка 2, через 2 месяца после перевивки объем опухоли у животных обеих опытных групп был меньше наблюдаемого в контроле, однако тенденция к статистически значимым различиям была только в случае штамма № 100: у мышей этой группы объем опухоли был в 2,7 раза меньше контроля (Me 6,6 [LQ; UQ 2,2; 10,2] и 17,7 [LQ; UQ 11,$4 ; 22,1] \mathrm{cm}^{3}$ соответственно, $\left.\mathrm{p}=0,051\right)$, а после введения штамма № 228 - в 1,9 раза меньше (Me 9,1 [LQ; UQ 3,25; 14,85] $\mathrm{cm}^{3}$ ). 


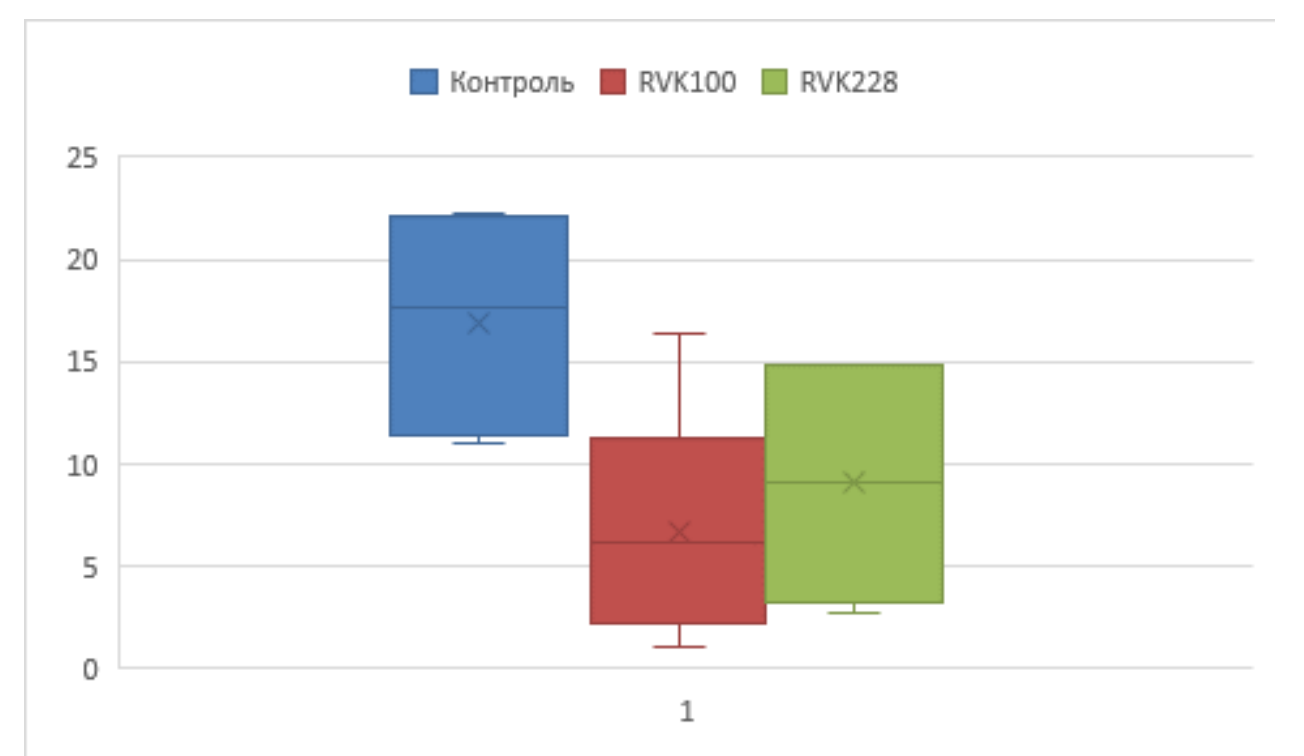

Рис. 2. Объем опухолей на 60-й день после перевивки (Мe); ось $Y$-объем опухоли (см $\left.{ }^{3}\right)$

Результаты определения показателей клеточного иммунитета мышей опытных и контрольной групп представлены на рисунке 3. Т-лимфоциты содержатся в крови бестимусных мышей в минимальном количестве, однако они все же присутствуют, возможно, за счет клеток, содержащихся в Т-зонах лимфоузлов и селезенки. Обращает на себя внимание резкое возрастание содержания NK-клеток в крови опухоленосителей по сравнению с интактными бестимусными мышами (с $1 \%$ до 15-17\%), при этом у животных опытных и контрольной групп оно не различается. Кроме того, у мышей с опухолями независимо от применения RVK по сравнению с интактными животными возрастает в 2-3 раза популяция не идентифицируемых данной панелью лимфоцитов. Их количество составляло $10-12 \%$, они располагались в лимфоцитарном гейте, однако не относились ни к одной из субпопуляций (ТB-NK-клеткам); для их характеристики необходима более развернутая панель антител.

Количество наиболее многочисленной популяции лимфоцитов, а именно Вклеток, в крови мышей-опухоленосителей снижено по сравнению с интактными, но при этом у мышей, получавших RVK штамма № 100, их содержание выше, чем у контрольных опухоленосителей (Ме 67 и 54 соответственно). В220 обычно используется как В-клеточный маркер мышей, хотя он эксперссирован и на других видах лимфоцитов и может рассматриваться как аналог CD45 человека (т.е. панлейкоцитарный антиген). CD23, как и у человека, является маркером активированных В-лимфоцитов. Как видно из рисунка 3 , у мышей-опухоленосителей обнаружено снижение как B220+, так и CD23+ по сравнению с интактными животными, однако среди сравниваемых групп максимальное количество обеих популяций обнаружено у мышей, получавших RVK № 100, хотя статистически значимых 
различий выявить не удалось. Количество лимфоцитов с мембранным рецептором $\operatorname{IgM}$ составляло от $0,2 \%$ до $0,37 \%$ от всех лимфоцитов.

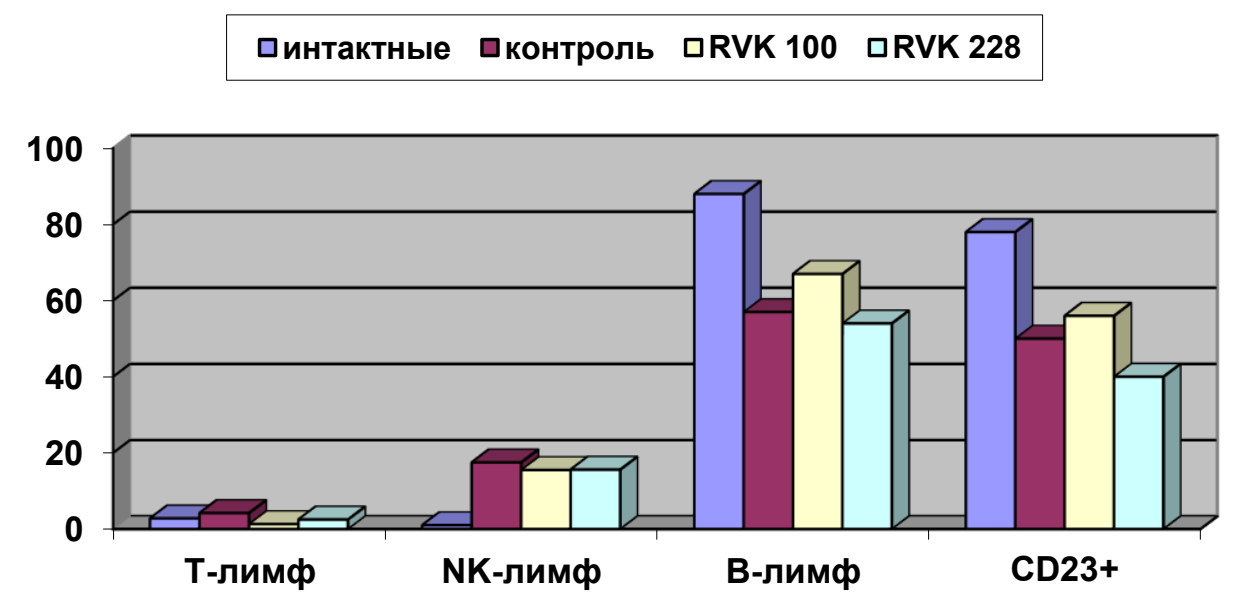

Рис. 3. Влияние введения RVK на показатели клеточного иммунитета у мышей, ось $Y$ - \%

Механизмы полученного эффекта, как мы полагаем с учетом использованной модели бестимусных мышей, могут быть связаны, прежде всего, с прямым онколитическим действием вирусов, возможно, осуществляемым через рецепторы опухолевых клеток [10]. Так, в работе C.A. Guerrero (2016), выполненной на культурах клеток, установлено, что свежевыделенные или коллекционные штаммы ротавирусов при адаптации к росту на линиях опухолевых клеток могут взаимодействовать с такими рецепторами, как PD1, HSP70, интегрины, колокализация которых с вирусными антигенами была выявлена авторами с помощью конфокальной микроскопии. В той же работе показано, что ротавирусы, инфицирующие клетки опухолевых линий, вызывают конденсацию хроматина, фрагментацию ДНК и апоптоз, сопровождающийся инактивацией PARP-1, c последующим лизисом и синцитиеобразованием, причем активность адаптированных штаммов отличалась от активности свежевыделенных. Кроме того, она различалась в зависимости от клеток-мишеней, что отражает генетическую гетерогенность ротавирусов, вызванную мутациями или реассортиментом в ходе их адаптации. По данным авторов, адаптация ротавирусов, полученных из различных источников, после многократных пассажей на опухолевых клетках может привести к получению штаммов, высокоактивных против них, хотя нельзя не отметить, что на культуре аденокарцимномы толстой кишки Сасо-2 их рост оказался хуже, чем на других, т.е. тропность к клеткам, происходящим из кишечного эпителия, была незначительной [11].

Поскольку вышеназванные рецепторы экспрессированы на многих опухолевых клетках, круг мишеней для ротавирусов может быть весьма широким и не обязательно тканеспецифичным. В этом плане не исследован EGFR, экспрессированный на клетках 
использованной нами линии [12], также представляют несомненный интерес HSP рецепторы [11]. В дальнейшем такое исследование может быть проведено на PDX-ксенографтах (patientderived xenografts) [13] или с использованием «локальной гуманизации» иммунодефицитных мышей с помощью мезенхимальных стволовых клеток человека [14].

Кроме того, по-видимому, не следует полностью отвергать и вклад иммунной системы, несмотря на то, что у бестимусных мышей отсутствует полноценное Т-клеточное звено. При введении вирусов у них могут стимулироваться факторы врожденного иммунитета, а полученный эффект сопровождается активацией В-клеточного звена. Как в данной работе, так и в других описано выраженное повышение уровня NK-клеток в крови и селезенке бестимусных мышей с опухолевыми ксенографтами $[13,15]$.

Заключение. Итак, на модели эпидермоидной карциномы вульвы человека, трансплантированной бестимусным мышам, установлено торможение ее роста под действием RVK, что свидетельствует о наличии у них онколитических свойств, а также, возможно, опосредовано через иммунную систему, представленную у бестимусных мышей преимущественно В-звеном. Такое действие выявлено в большей степени у штамма № 100.

\section{Список литературы}

1. Buijs P.R., Verhagen J.H., van Eijck C.H., van den Hoogen B.G. Oncolytic viruses: from bench to bedside with a focus on safety. Hum Vaccin Immunother. 2015. vol. 11. P. 1573-1584. DOI: 10.1080/21645515.2015.1037058.

2. Mohamadi A., Pagès G., Hashemzadeh M.S. The important role of oncolytic viruses in common cancer treatments. Current Cancer Therapy Reviews. 2020. vol. 16. no. 4. P. 292-305. DOI: $10.2174 / 1573394716666200211120906$.

3. Сосновцева А.О., Гриненко Н.Ф., Липатова А.В., Чумаков П.М., Чехонин В.П. Онколитические вирусы в терапии злокачественных глиом // Биомедицинская химия. 2016. Т. 62. № 4. C. 376-390. DOI: 10.18097/PBMC20166204376.

4. Чумаков П.М., Морозова В.В., Бабкин И.В., Байков И.К, Нетесов С.В. Тикунова Н.В. Онколитические энтеровирусы // Молекулярная биология. 2012. Т. 46. № 5. С. 712-725.

5. Zhang B., Cheng P. Improving antitumor efficacy via combinatorial regimens of oncolytic virotherapy. Mol Cancer. 2020. vol. 19. no. 158. DOI: 10.1186/s12943-020-01275-6.

6. Zhang J., Zhang Y., Zhang Z. Prevalence of human papillomavirus and its prognostic value in vulvar cancer: A systematic review and meta-analysis. PLoS ONE. 2018. vol. 13. no. 9.e0204162. DOI: 10.1371 journal. pone.0204162. 
7. Колпаков С.А., Колпакова Е.П. Новая группа ротавирусов человека семейства Reoviridae // Живые и биокосные системы. 2014. T. 10. C. 6.

8. Ситковская А.О., Филиппова С.Ю., Златник Е.Ю., Колпаков С.А., Колпакова Е.П., Межевова И.В., Бондаренко Е.С., Игнатов С.Н., Новикова И.А., Росторгуев Э.Е., Кит О.И. Цитотоксическое действие неклассифицированных ротавирусов группы К на культуры клеток T98G и U87MG in vitro // Цитология. 2020. Т. 62. № 3. С. 1-12. DOI: $10.31857 / \mathrm{S} 0041377120030062$.

9. Колпаков С.А., Колпакова Е.П., Златник Е.Ю., Непомнящая Е.М., Новикова И.А., Шульгина О.Г., Сагакянц А.Б., Сидоренко Ю.С. Оценка противоопухолевой активности штаммов новой группы ротавирусов семейства Reoviridae на модели перевиваемой меланомы мышей // Вопросы онкологии. 2020. Т. 66. № 6. С. 712-7. DOI: 10.37469/0507-3758-2020-66-6712-717.

10. Jayawardena N., Burga L.N., Poirier J.T., Bostina M. Virus -receptor interactions: structural insights for oncolytic virus development. Oncolytic Virother. 2019. vol. 8. P. 39-56. DOI: 10.2147/OV.S218494.

11. Guerrero C.A., Guerrero R.A., Silva E., Acosta O., Barreto E. Experimental adaptation of rotaviruses to tumor cell lines. PLoS One. 2016. vol. 11. no. 2.e0147666. DOI: 10.1371/journal.pone.0147666.

12. Dong A., Wodziak D., Lowe A.W. Epidermal growth factor receptor (EGFR) signaling requires a specific endoplasmic reticulum thioredoxin for the post-translational control of receptor presentation to the cell surface. J. Biol Chem. 2015. vol. 290. no. 13. P. 8016-8027. DOI: 10.1074/jbc.M114.623207.

13. Кит О.И., Колесников Е.Н., Максимов А.Ю., Протасова Т.П., Гончарова А.С., Лукбанова Е.А. Методы создания ортотопических моделей рака пищевода и их применение в доклинических исследованиях // Современные проблемы науки и образования. 2019. № 2. [Электронный pecypc]. URL: https://science-education.ru/ru/article/view?id=28606 (дата обращения: 288.01.2022).

14. Ж Жукова Г.В., Шихлярова А.И., Сагакянц А.Б., Протасова Т.П. О расширении вариантов использования мышей Balb/c Nude для экспериментального изучения злокачественных опухолей человека in vivo // Южно-российский онкологический журнал. 2020. T. 1. № 2. С. 28-35. DOI: 10.37748/2687-0533-2020-1-2-4.

15. Златник Е.Ю., Максимов А.Ю., Гончарова А.С., Карнаухов Н.С. Разработка моделей роста злокачественных опухолей человека для клеточной иммунотерапии // Российский иммунологический журнал. 2019. Т. 22. № 2-2. C. 775-7. DOI: 10.31857/S102872210006702-7. 